\title{
ANALISA PRODUKTIVITAS TENAGA KERJA PADA PEKERJAAAN PENUTUP ATAP
}

\author{
Mulyadi $^{1)}$, Hasnawati ${ }^{1)}$ \\ ${ }^{1)}$ STKIP Bina Bangsa Meulaboh \\ Jl. Meulaboh - Tapaktuan Peunaga Cut Ujong Kec. Meurebo Kab. Aceh Barat Aceh \\ Corresponding Author: mulyoung@yahoo.co.id
}

\begin{abstract}
Abstrak
Produktivitas merupakan salah satu faktor penting dalam menentukan keberhasilan suatu pekerjaan konstruksi. Peningkatan produktivitas akan mengurangi waktu pekerjaan, dan itu berarti akan mereduksi biaya. Secara umum, nilai produktivitas ditentukan oleh faktor besaran volume pekerjaan, waktu pelaksanaan, dan jumlah tenaga kerja. Agar pekerjaan dapat diselesaikan dengan baik, diperlukan upaya perencanaan dengan memperhatikan faktor-faktor tersebut. Untuk itu, penelitian ini dilakukan untuk mengetahui nilai produktivitas pada salah satu komponen pekerjaan bangunan gedung yaitu pekerjaan penutup atap. Objek yang diteliti adalah pekerjaan pemasangan penutup atap dan pemasangan rabungnya 4 (empat) lokasi proyek yaitu Proyek Pembangunan Ruko 4 x 25 di Meulaboh Aceh Barat, Pembangunan Gedung Biro Rektorat \& Administrasi STKIP Bina Bangsa Getsempena Banda Aceh, Pembangunan Gedung Kuliah STIKes Getsempena Lhoksukon Aceh Utara dan Pembangunan Gedung Rektorat STIKes Bina Nusantara Idi Aceh Timur. Material atap menggunakan bahan zincalume. Volume pekerjaan atap direncanakan seluas 2022,38 $\mathrm{m}^{2}$. Penelitian dilakukan melalui observasi lapangan dengan mencatat langsung volume pekerjaan, durasi setiap tahap pekerjaan, dan jumlah tanaga kerja yang terlibat. Hasil analisis menunjukkan bahwa nilai produktivitas untuk pekerjaan pemasangan atap diperoleh sebesar $12,061 \mathrm{~m}^{2} / \mathrm{jam}$ atau $96,487 \mathrm{~m}^{2} /$ hari dan untuk pekerjaan pemasangan rabung atap diperoleh sebesar 13,926 m/jam atau $111.405 \mathrm{~m} / \mathrm{hari}$.
\end{abstract}

Kata kunci: produktivitas, tenaga kerja, pekerjaan penutup atap

\begin{abstract}
Productivity is one of the important factors in determining the success of a construction job. Increased productivity will reduce work time, and that will reduce costs. In general, the value of productivity is determined by factors in the amount of work volume, time of implementation, and the number of workers. In order for the work to be completed properly, planning efforts are needed by taking into account these factors. For this reason, this study was conducted to determine the value of productivity in one of the components of building work, namely roof cover work. The objects studied were the work of installing roof coverings and the installation of 4 (four) project locations, namely the $4 \times 25$ Shophouse Construction Project in Meulaboh West Aceh, Building of the Rector \& Administration Bureau of STKIP Building Nation Getsempena Banda Aceh, Construction of the Getsempena STIKes College Building Lhoksukon North Aceh and Construction of the East Aceh Bina Nusantara Idi STIKes Building. Roof material using zincalume material. The roof work volume is planned to be $2022.38 \mathrm{~m} 2$. The research was conducted through field observations by recording the work volume directly, the duration of each stage of work, and the number of workforce involved. The results of the analysis show that the productivity value for roofing work is obtained at 12,061 m2/hour or $96,487 \mathrm{~m} 2 /$ day and for roof joint installation work is obtained at 13,926 m/ hour or $111,405 \mathrm{~m} /$ day.
\end{abstract}

Keywords: productivity, labor, roof cover work 


\section{PENDAHULUAN}

Sumber daya adalah faktor penentu keberhasilan kontruksi tersebut. Sumber daya yang berpengaruh dalam proyek terdiri dari man, materials, machine, money dan method. Pekerjaan kontrukssumber daya manusia merupakan salah satu faktor yang terpenting dalam pekerjaan kontruksi. Pekerjaan apapun apabila tidak ditunjang dengan sumber daya manusia (SDM) yang tepat dalam hal kualitas dan produktivitas, tidak akan memberikan hasil yang maksimal dan memuaskan dalam sebuah proyek. Penggunaan sumber daya manusia yang kurang efisien/bijaksana bisa mengakibatkan sebuah kerugian yang besar pada proyek kontruksi.

Upaya mengatur atau mengelola penggunaan SDM agar tepat, kontraktor harus mengetahui tingkat produktivitas masing-masing pekerja. Proyek kontruksi yang berhasil sangat memerlukan produktifikas tenaga kerja yang sangat baik/tepat. Besarnya keuntungan atau kerugian suatu proyek dipengaruhi oleh produktivitas tenaga kerja. Pelaksanaan dilapangan, ini kadang-kadang dapat terjadi karena tenaga kerja kurang efektif dalam pekerjaannya. Contoh tindakan yang menyebabkan pekerjaan tidak efektif termasuk pengangguran, mengobrol, makan, merokok, istirahat, yang semuanya dilakukan selama jam kerja.

Selain kegiatan yang kurang efektif di atas yang menyebabkan hambatan produktivitas, masih ada faktor lain yang mempengaruhi produktivitas tenaga kerja. Faktor-faktor ini termasuk kondisi lapangan dan fasilitas pendukung, keterampilan karyawan, faktor usia atau usia pekerja, kesesuaian upah, pengalaman dalam pekerjaan, kesehatan pekerja, koordinasi dan perencanaan, jenis kontrak kerja, manajerial atau manajemen lapangan. Variabel-variabel ini adalah hal-hal yang tentunya menjadi variabel yang mempengaruhi produktivitas kerja. Oleh karena itu, dalam upaya untuk menganalisis produktivitas tenaga kerja harus dipertimbangkan variabel yang mungkin mempengaruhi tingkat produktivitas.

Penyelesaian konstruksi bangunan dilakukan secara bertahap sesuai dengan komponen kerja. Secara umum, komponen-komponen ini dapat dikelompokkan menjadi komponen struktural dan komponen non-struktural. Komponen struktural berhubungan dengan bagian konstruksi yang berfungsi untuk menahan dan memikul beban bangunan, sedangkan komponen non-struktural terkait dengan komponen arsitektur dan utilitas bangunan. Pelaksanaan pekerjaan konstruksi yang terencana adalah salah satu upaya untuk mencapai keberhasilan penyelesaian proyek konstruksi. Perencanaan umumnya terkait dengan penyediaan sumber daya proyek, seperti tenaga kerja, bahan dan peralatan, dan berbagai sumber daya proyek lainnya. Pada tahap implementasi, sinergi antara sumber daya ini akan menghasilkan produktivitas kerja, yang akan menjadi salah satu tolok ukur untuk keberhasilan penyelesaian suatu proyek.

Peningkatan atau penurunan nilai produktivitas sangat ditentukan oleh kemampuan tenaga kerja yang terlibat dalam menyelesaikan pekerjaan dalam jangka waktu tertentu. Produktivitas akan meningkat jika volume pekerjaan dapat diselesaikan lebih cepat daripada target 
waktu yang ditentukan dan sebaliknya. Secara umum, nilai produktivitas ditentukan oleh faktor jumlah volume pekerjaan, waktu pelaksanaan, dan jumlah pekerja.

Studi tentang produktivitas diperlukan terutama jika dikaitkan dengan proses standardisasi material, tenaga kerja dan persyaratan peralatan untuk suatu pekerjaan. Standar ini akan menjadi panduan bagi perencana, baik dalam perencanaan anggaran dan dalam merencanakan waktu penyelesaian proyek. Berdasarkan latar belakang ini, penelitian ini bertujuan untuk menganalisis nilai produktivitas di salah satu komponen non-struktural suatu bangunan. Secara khusus, penelitian dilakukan pada komponen penutup atap.

Berdasarkan permasalahan tersebut, penulis akan melakukan penelitian tentang produktivitas tenaga kerja pada tiga lokasi yaitu proyek pembangunan Ruko 4x25m di Meulaboh Aceh Barat, Gedung Biro Rektorat \& Administrasi STKIP Bina Bangsa Getsempena Banda Aceh, Gedung Kuliah STIKes Getsempena Lhoksukon Aceh Utara, Gedung Rektorat STIKes Bina Nusantara Idi Aceh Timur.

Penyelesaian sebuah konstruksi bangunan gedung dilakukan dalam tahapan-tahapan menurut komponen pekerjaan. Secara umum, komponen tersebut dapat dikelompokkan menjadi komponen structural dan komponen non-struktural (Anonim, 2007). Komponen structural berkaitan dengan bagian dari konstruksi yang berfungsi menahan dan meneruskan beban bangunan, sedang komponen non-struktural berkaitan dengan komponen arsitektur dan utilitas bangunan. Pelaksanaan pekerjaan konstruksi yang terencana dengan baik merupakan salah satu upaya mencapai kesuksesan penyelesaian sebuah proyek konstruksi.Perencanaan tersebut umumnya berkaitan dengan penyediaan sumber daya proyek, seperti tenaga kerja, material dan peralatan, dan berbagai sumber daya proyek lainnya. Pada tahap pelaksanaan, sinergi antar sumber daya tersebut akan menghasilkan sebuah produktivitas kerja, yang akan menjadi salah satu tolok ukur dalam bagi kesuksesan penyelesaian sebuah proyek.

Peningkatan atau penurunan nilai produktivitas sangat ditentukan oleh kemampuan tenaga kerja yang terlibat dalam menyelesaikan suatu pekerjaan dalam kurun waktu tertentu. Produktivitas akan meningkat jika volume sebuah pekerjaan dapat diselesaikan lebih cepat dari target waktu yang ditentukan dan demikian pula sebaliknya. Secara umum, nilai produktivitas ditentukan oleh faktor besaran volume pekerjaan, waktu pelaksanaan,dan jumlah tenaga kerja. Agar pekerjaan dapat diselesaikan dengan baik, diperlukan upaya perencanaan dengan memperhatikan faktorfaktor tersebut.

Kajian mengenai produktivitas sangat diperlukan terutama bila dikaitkan dengan proses standarisasi kebutuhan material, tenaga kerja, dan peralatan untuk sebuah pekerjaan. Standar tersebut akan menjadi pedoman bagi seorang perencana, baik dalam perencanaan anggaran maupun dalam perencanaan waktu penyelesaian sebuah proyek. Berdasarkan latarbelakang tersebut, penelitian ini ditujukan untuk menganalisis nilai produktivitas pada salah satu komponen non-struktural bangunan gedung. Secara spesifik, kajian dilakukan pada komponen penutup atappenelitian boleh menggunakan sub-title sesuai kebutuhan penulis dalam menjelaskan cara melakukan penelitian dan dapat disajikan dengan referensi yang digunakan sesuai dengan tahapan penelitian. 
Bangunan gedung adalah wujud fisik hasil pekerjaan konstruksi yang menyatu dengan tempat dan kedudukannya, sebagian atau seluruhnya berada diatas dan/atau didalam tanah dan/atau air, yang berfungsi sebagai tempat manusia melakukan kegiatan, baik untuk hunian atau tempat tinggal, kegiatan keagamaan, kegiatan usaha, kegiatan sosial, budaya, maupun kegiatan khusus (Anonim, 2007). Konstruksi bangunan gedung terdiri dari sejumlah komponen yang secara umum dapat dikelompokkan dalam komponen structural dan komponen non-struktural.

Konstruksi atap merupakan salah satu komponen pembentuk sebuah bangunan gedung. Secara umum atap berfungsi sebagai penutup seluruh ruangan yang ada dibawahnya terhadap pengaruh panas, hujan, debu, kotoran, angin, dan sebagainya. Pemilihan bentuk dan jenis atap harus disesuaikan dengan bentuk bangunan dibawahnya, iklim setempat, biaya, serta bahan bangunan yang tersedia didaerah tersebut (Kusjuliadi, 2007).

Pada dasarnya, ada dua komponen utama sebagai penyusun atap, yaitu struktur atap dan penutup atap. Struktur atap merupakan susunan rangka batang yang berfungsi sebagai pendukung atau penahan beban penutup atap. Struktur atap meliputi kuda-kuda atap dan rangka atap. Ada banyak bahan yang dapat digunakan sebagai penutup atap, diantaranya meliputi atap genteng, asbes, sirap, polikarbonat, seng, alumunium dan lain- lain (Kusjuliadi,2007). Dari segi bentuk, atap yang lazim digunakan adalah atap datar, atap sandar, atap pelana, atap perisai, atap tenda, atap joglo, atap setengah bola, atap silang, dan atap gabungan (Supribadi,1993)

Produktivitas dapat diartikan sebagai perbandingan antara output (hasil produksi) terhadap input (komponen produksi : tenagakerja, bahan, peralatan, dan waktu). Jadi dalam analisis produktivitas dapat dinyatakan sebagai rasio antara output terhadap input dan waktu (jam atau hari). Bila input dan waktu kecil maka output semakin besar sehingga produktivitas semakin tinggi (Anonim, 2013).

$$
P=\frac{V}{n T}
$$

Dimana:

$P=$ produktivitas $\left(\mathrm{m}^{2} /\right.$ hari $)$;

$V=$ volume pekerjaan per satuan waktu $\left(\mathrm{m}^{2}\right)$

$N=$ jumlah tenaga kerja (orang); d

$T=$ waktu kerja efektif (hari).

Pekerjaan penutup atap meliputi kudakuda/rangka dan penutup atap. Bahan kuda-kuda atap ada dua jenis yaitu bahan kayu dan bahan baja ringan. Bahan penutup atap antara lain bahan semen (genteng semen) dan seng (seng genteng). Angka produktivitas tenaga kerja terhadap pekerjaan struktur rangka atap baja ringan terhadap pekerjaan rangkaatap kayu ada sedikit perbedaan, yaitu nilai produktivitas tenaga kerja terhadap pekerjaan rangka atap baja ringan lebih besar dari pada nilai produktivitas tenaga kerja terhadap pekerjaan rangka atap kayu (Tisnawan dan Hadi, 2016).

Pengukuran produktivitas tenaga kerja menurut sistem penghasilan perorangan / per-orang atau per jam secara luas diterima, tetapi dari sudut pandang pengawasan harian, pengukuran ini umumnya tidak memuaskan, karena variasi dalam jumlah yang diperlukan untuk menghasilkan satu unit produk. berbeda. Oleh karena itu, metode pengukuran waktu kerja (jam, hari atau tahun) digunakan. Pengeluaran dikonversikan ke dalam unit kerja yang biasanya didefinisikan sebagai jumlah pekerjaan yang dapat dilakukan dalam satu jam oleh pekerja tepercaya yang bekerja sesuai dengan penerapan standar. Karena hasil dan masukan dapat diekspresikan pada waktunya, produktivitas kerja dapat 
dinyatakan sebagai indeks yang sangat sederhana (Muchdarsyah, 2003).

Pengukuran waktu tenaga kerja adalah: hasil dalam jam-jam standart masukan dalam jam-jam standart

Waktu efektif adalah waktu ketika pekerja melakukan kegiatan yang dapat dikualifikasikan sebagai bekerja. Waktu yang tidak efektif adalah waktu ketika pekerja melakukan kegiatan yang disesuaikan yang berkualitas sebagai tidak bekerja. Kualifikasi aktivitas pekerja dalam metode ini tidak mutlak, yang berarti dapat menyesuaikan dengan kondisi di lapangan untuk mendapatkan data yang dibutuhkan.

\section{METODE PENELITIAN}

\section{OBJEK PENELITIAN}

Penelitian ini dilakukan secara khusus pada komponen peutup atap. Penelitian mengambil lokasi pada proyek Pembangunan Gedung dan Ruko di Aceh. Bahan penutup atap yang digunakan adalah jenis atap zincalume dengan total volume yang direncanakan seluas 2022,38 $\mathrm{m}^{2}$. Lingkup observasi difokuskan pada 4 lokasi pekerjaan atap yang terdapat pada bangunan gedung yang ditinjau.

Agar penelitian ini lebih fokus pada komponen penutup atap. Lingkup observasi penelitian ini pada 4 (empat) lokasi yaitu sebagai berikut :

- Proyek Pembangunan Ruko 4 x 25 di Meulaboh Aceh Barat 100,00 m²;

- Pembangunan Gedung Biro Rektorat \& Administrasi STKIP Bina Bangsa Getsempena Banda Aceh $640 \mathrm{~m}^{2}$;

- Pembangunan Gedung Kuliah STIKes Getsempena Lhoksukon Aceh Utara $570,73 \mathrm{~m}^{2}$ dan
- Pembangunan Gedung Rektorat STIKes Bina Nusantara Idi Aceh Timur $711,65 \mathrm{~m}^{2}$.

Pengamatan tenaga kerja dilakukan pada jam 08.00-16.00 dengan istirahat satu jam yaitu jam 12.00-13.00. Obyek pengamatan hanya pada pekerjaan struktur rangka dan penutup atap baja ringan.

\section{PENGUMPULAN DATA}

Penelitian ini menggunakan dua jenis data yaitu data primer dan data sekunder. Data primer didapatkan melalui hasil observasi langsung di lapangan. Pencatatan dan pengukuran yang dilakukan terdiri dari pengukuran volume pekerjaan, pencatatan jumlah tenaga kerja, dan pengukuran waktu kerja efektif penyelesaian pekerjaan pada setiap segmen pekerjaan pemasangan penutup atap. Data sekunder diperoleh dari dokumentasi proyek, berupa informasi seperti gambar rencana atap, daftar pekerjaan dan volume, dan Rencana Kerja dan Syarat-syarat (RKS).

\section{PENGOLAHAN DATA DAN ANALISIS}

Data yang telah terkumpul diolah untuk mendapatkan nilai produktivitas. Pengolahan data diawali dengan membuat pengelompokan data sesuai dengan lokasi pekerjaan penutup atap. Data volume, jumlah tenaga kerja, dan waktu efektif menjadi masukan untuk mendapatkan nilai produktivitas. Proses analisis dilakukan dengan menggunakan persamaan 1. Nilai produktivitas secara keseluruhan akan ditentukan berdasarkan nilai rerata yang diperoleh dari 4 lokasi tinjauan.

\section{HASIL DAN PEMBAHASAN}

\section{Hasil Observasi Lapangan}

Hasil Pelaksanaan pekerjaan pemasangan penutup atap dilakukan pada 4 lokasi atap bangunan. Pekerjaan yang dilakukan pada 
komponen penutup atap tersebut terdiri dari 2 jenis pekerjaan yaitu pemasangan penutup atap dan pemasangan rabung atap. Material penutup atap yang digunakan adalah zincalume dengan dimensi panjang efektif $1200 \mathrm{~mm}$, lebar efektif $720 \mathrm{~mm}$ (toleransi \pm $5 \mathrm{~mm}$ ), luas per lembar $1,62 \mathrm{lbr} / \mathrm{m}^{2}$ dan berat per $\mathrm{m}^{2} 4,5 \mathrm{~kg} / \mathrm{m}^{2}$.
Untuk rabung panjang $375 \mathrm{~mm}$ dan diameter $140 \mathrm{~mm}$. Gambar rencana pemasangan dan dimensi material dapat dilihat pada Gambar 1 dan Gambar 2. Proses pelaksanaan pemasangan penutup atap dapat dilihat pada Gambar 3.
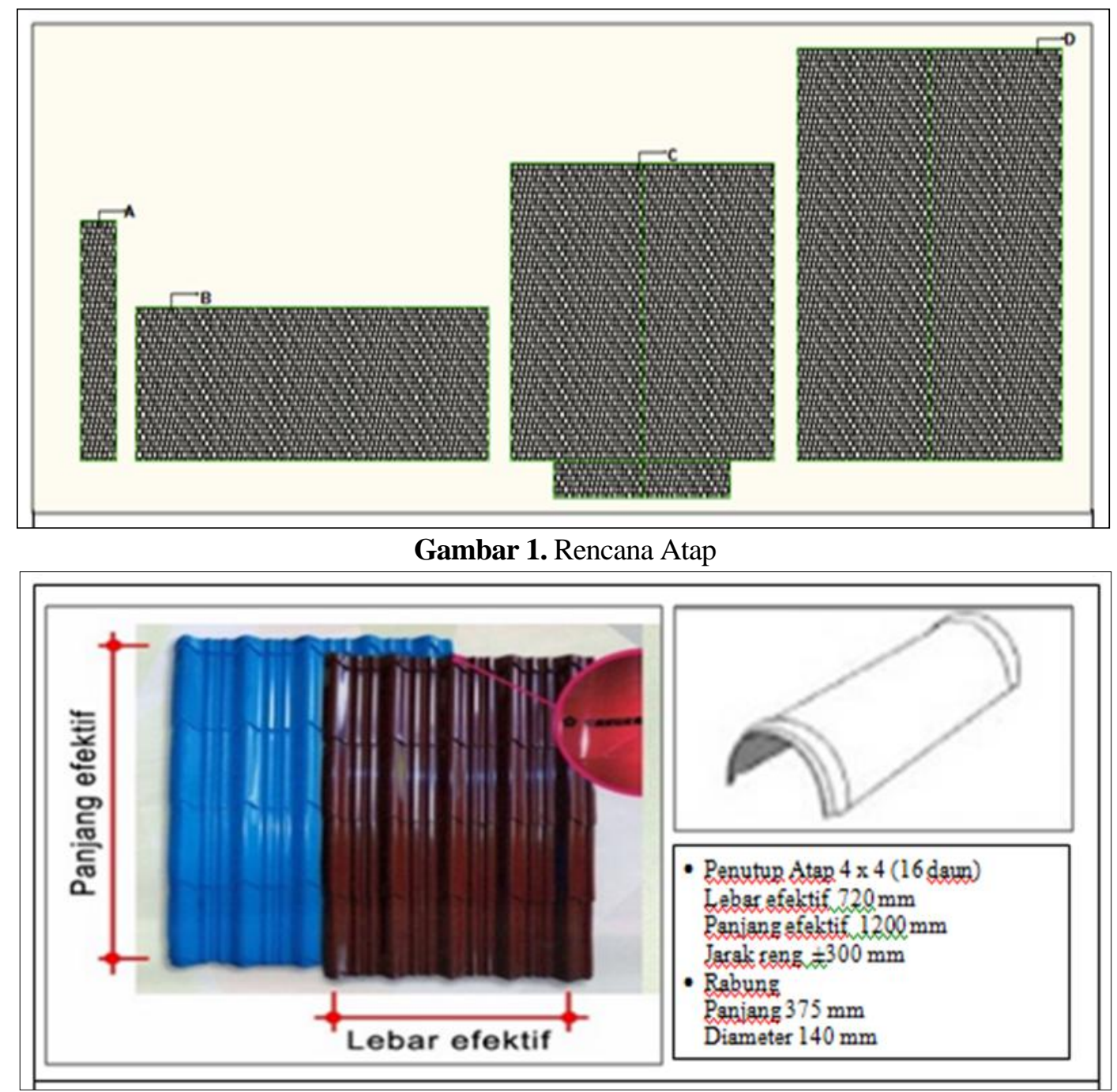

Gambar 2. Dimensi Material 


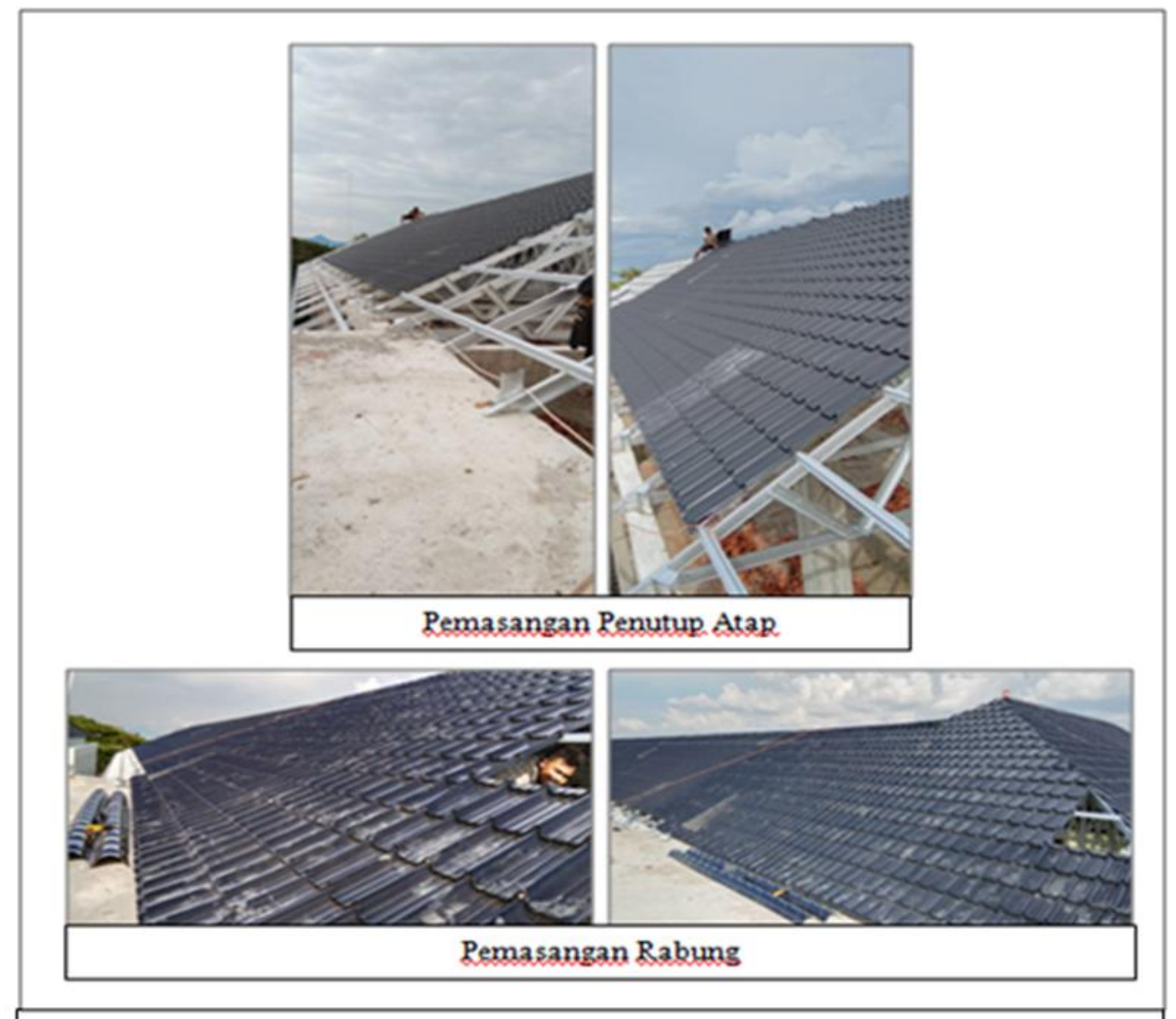

Gambar 3. Tahap Pengerjaan Pkerjaan Penutup Atap dan Pemasangan Rabung

\section{Produktivitas Pekerjaan}

Nilai produktivitas ditentukan oleh jumlah volume pekerjaan, jumlah pekerja, dan waktu kerja yang efektif. Dari hasil pengamatan lapangan, informasi tentang jumlah volume, jumlah pekerja, dan waktu kerja yang efektif ditunjukkan dalam Tabel 1 dan Tabel 2.

Analisis produktivitas kerja dari penutup atap dimulai dengan menghitung volume pekerjaan yang dibahas sebelumnya. Kemudian dibandingkan dengan waktu kerja dan waktu efektif dalam menyelesaikan pekerjaan di setiap lokasi pemasangan penutup atap. Hasil produktivitas di setiap lokasi pekerjaan pemasangan penutup atap dapat dilihat pada Tabel 3.
Tabel 1. Pekerjaan Pemasangan Penutup Atap

\begin{tabular}{cccccc}
\hline & Lokasi & \multicolumn{2}{c}{ Volume enaga Ker } & \multicolumn{2}{c}{ Waktu Efektif } \\
\cline { 5 - 6 } No & Pekerjaan & m2 & (orang) & (menit) & (jam) \\
\hline 1 & Lokasi A & 100.00 & 4 & 125.75 & 2.096 \\
\hline 2 & Lokasi B & 640.00 & 4 & 811.45 & 13.524 \\
\hline 3 & Lokasi C & 570.73 & 4 & 676.25 & 11.271 \\
\hline 4 & Lokasi D & 711.65 & 4 & 902.75 & 15.046 \\
\hline
\end{tabular}

Tabel 2. Pekerjaan Pemasangan Rabung

\begin{tabular}{cccccc}
\hline & Lokasi & \multicolumn{2}{c}{ Volume enaga Ker } & \multicolumn{2}{c}{ Waktu Efektif } \\
\cline { 5 - 6 } No & Pekerjaan & m2 & (orang) & (menit) & (jam) \\
\hline 1 & Lokasi A & 0.00 & 2 & 0.00 & 0.000 \\
\hline 2 & Lokasi B & 0.00 & 2 & 0.00 & 0.000 \\
\hline 3 & Lokasi C & 36.00 & 2 & 78.75 & 1.313 \\
\hline 4 & Lokasi D & 43.00 & 2 & 91.25 & 1.521 \\
\hline
\end{tabular}


Tabel 3. Hasil Produktivitas Pada Setiap Lokasi

\begin{tabular}{cccccc}
\hline & Lokasi & \multicolumn{2}{c}{ Penutup Atap } & \multicolumn{2}{c}{ Rabung } \\
\cline { 3 - 6 } No. & Pekerjaan & $(\mathrm{m} 2$ jam) & $(\mathrm{m} 2$ hari) & (m jam) & (m/hari) \\
\hline 1 & Lokasi A & 11.928 & 95.427 & 0 & 0 \\
\hline 2 & Lokasi B & 11.831 & 94.645 & 0 & 0 \\
\hline 3 & Lokasi C & 12.659 & 101.276 & 13.714 & 109.714 \\
\hline 4 & Lokasi D & 11.825 & 94.598 & 14.137 & 113.096 \\
\hline & Rerata & 12.061 & 96.487 & 13.926 & 111.405 \\
\hline
\end{tabular}

Hasil analisis menunjukkan bahwa nilai produktivitas untuk pekerjaan penutup atap diperoleh rata-rata sebesar $12,061 \mathrm{~m}^{2} /$ jam atau $96,487 \mathrm{~m}^{2} /$ hari. Produktivitas terbesar terlihat pada Lokasi $\mathrm{C}$ dan yang terkecil pada Lokasi D. Nilai produktivitas pekerjaan pemasangan rabung atap diperoleh sebesar 13,926 $\mathrm{m} / \mathrm{jam}$ atau $111.405 \mathrm{~m} / \mathrm{hari}$. Produktivitas terbesar terlihat pada Lokasi D dan yang terkecil pada Lokasi C. Pada lokasi A dan B tidak ada pemasangan rabung. Pada pelaksanaan pekerjaan penutup atap dan rabung, jumlah tenaga kerja yang digunakan sama pada seluruh segmen, sehingga nilai produktivitas cenderung ditentukan oleh besaran rasio antara volume pekerjaan dan waktu efektif pelaksanaan. Dengan demikian, bila jumlah volume pekerjaan dapat diselesaikan dalam waktu yang lebih singkat maka nilai produktivitas akan meningkat.

\section{KESIMPULAN}

Dari hasil analisis yang telah dilakukan, penelitian ini menyimpulkan bahwa untuk pekerjaan penutup atap, nilai produktivitas rata- rata yang diperoleh sebesar 12,061 $\mathrm{m}^{2} /$ jam atau 96,487 $\mathrm{m}^{2} /$ hari dan untuk pekerjaan pemasangan rabung atap, nilai produktivitas rata-rata yang diperoleh sebesar $13,926 \mathrm{~m} / \mathrm{jam}$ atau $111,405 \mathrm{~m} / \mathrm{hari}$. Nilai produktivitas cenderung ditentukan oleh besaran rasio antara volume pekerjaan dan waktu efektif pelaksanaan. Hal ini disebabkan oleh penggunaan jumlah tenaga kerja yang sama pada setiap segmen tinjauan. Dengan demikian, bila jumlah volume pekerjaan dapat diselesaikan dalam waktu yang lebih singkat maka nilai produktivitas akan meningkat.

Untuk kedepan atau penelitian selanjutnya agar bias dilakukan pada satu lokasi saja yang lumayan besar pekerjaan dan meliputi dua jenis bahan penutup atap, yaitu bahan spandek dan bahan genteng susun. Supaya didapat perbedaan dan acuan lebih baik lagi dalam pekerjaan penutup atap dan pemasangan rabung ini.

\section{DAFTAR NOTASI}

$P=$ produktivitas $\left(\mathrm{m}^{2} /\right.$ hari $)$

$V=$ volume pekerjaan per satuan waktu $\left(\mathrm{m}^{2}\right)$;

$n=$ jumlah tenaga kerja (orang); dan

$T=$ waktu kerja efektif (hari).

\section{DAFTAR PUSTAKA}

Anonim, 2007, Peraturan Menteri Pekerjaan Umum Nomor: No.45/PRT/M/2007 Tentang Pedoman Teknis Pembangunan Bangunan Gedung Negara.

Anonim, 2013, Peraturan Menteri Pekerjaan Umum Nomor: No.11/PRT/M/2013 Tentang Pedoman Analisis Harga Satuan Pekerjaan Bidang Pekerjaan Umum.

Kusjuliadi, D. 2007. Ragam Bentuk dan Perawatan Atap. Penebar Swadaya. Jakarta.

Muchdarsyah, S (2014) Produktivitas: Apa dan Bagaimana , Jakarta : Bumi Aksara.

Supribadi, 1993. Ilmu Bangunan Gedung, Bandung: Armico.

Tisnawati, R \& Hadi, S. 2016. Analisis Produktivitas tenaga kerja dan biaya pada pekerjaan pasangan rangka atap pada pembangunan perumahan panam view tipe 48,Jurnal Teknik Sipil Universitas Abdurrab vol 1 no 2. 